\title{
Interstage mortality after the Norwood procedure: Results of the multicenter Single Ventricle Reconstruction trial
}

\author{
Nancy S. Ghanayem, MD, ${ }^{\mathrm{a}}$ Kerstin R. Allen, ${ }^{\mathrm{b}}$ Sarah Tabbutt, MD, PhD, ${ }^{\mathrm{c}}$ Andrew M. Atz, MD, ${ }^{\mathrm{d}}$ \\ Martha L. Clabby, MD, ${ }^{\mathrm{e}}$ David S. Cooper, MD, ${ }^{\mathrm{f}}$ Pirooz Eghtesady, MD, ${ }^{\mathrm{g}}$ Peter C. Frommelt, MD, ${ }^{\mathrm{a}}$ \\ Peter J. Gruber, MD, ${ }^{c}$ Kevin D. Hill, MD, ${ }^{h}$ Jonathan R. Kaltman, MD, ${ }^{i}$ Peter C. Laussen, MBBS, ${ }^{j}$ \\ Alan B. Lewis, MD, ${ }^{\mathrm{k}}$ Karen J. Lurito, MD, ${ }^{1}$ L. LuAnn Minich, MD ${ }^{\mathrm{m}}$ Richard G. Ohye, MD, ${ }^{\mathrm{n}}$ \\ Julie V. Schonbeck, ${ }^{\mathrm{b}}$ Steven M. Schwartz, MD, ${ }^{\mathrm{o}}$ Rakesh K. Singh, MD, ${ }^{\mathrm{p}}$ and Caren S. Goldberg, MD, ${ }^{\mathrm{n}}$ for \\ the Pediatric Heart Network Investigators
}

Objective: For infants with single ventricle malformations undergoing staged repair, interstage mortality is reported at $2 \%$ to $20 \%$. The Single Ventricle Reconstruction trial randomized subjects with a single morphologic right ventricle undergoing a Norwood procedure to a modified Blalock-Taussig shunt (MBTS) or a right ventricle-to-pulmonary artery shunt (RVPAS). The aim of this analysis was to explore the associations of interstage mortality and shunt type, and demographic, anatomic, and perioperative factors.

Methods: Participants in the Single Ventricle Reconstruction trial who survived to discharge after the Norwood procedure were included $(n=426)$. Interstage mortality was defined as death postdischarge after the Norwood procedure and before the stage II procedure. Univariate analysis and multivariable logistic regression were performed adjusting for site.

Results: Overall interstage mortality was 50 of $426(12 \%)-13$ of $225(6 \%)$ for RVPAS and 37 of $201(18 \%)$ for MBTS (odds ratio [OR] for MBTS, 3.4; $P<.001$ ). When moderate to severe postoperative atrioventricular valve regurgitation (AVVR) was present, interstage mortality was similar between shunt types. Interstage mortality was independently associated with gestational age less than 37 weeks $(\mathrm{OR}, 3.9 ; P=.008)$, Hispanic ethnicity (OR, 2.6; $P=.04)$, aortic atresia/mitral atresia (OR, 2.3; $P=.03$ ), greater number of post-Norwood complications $(\mathrm{OR}, 1.2 ; P=.006)$, census block poverty level $(P=.003)$, and MBTS in subjects with no or mild postoperative AVVR (OR, $9.7 ; P<.001)$.

Conclusions: Interstage mortality remains high at $12 \%$ and is increased with the MBTS compared with the RVPAS if postoperative AVVR is absent or mild. Preterm delivery, anatomic, and socioeconomic factors are also important. Avoiding preterm delivery when possible and close surveillance after Norwood hospitalization for infants with identified risk factors may reduce interstage mortality. (J Thorac Cardiovasc Surg 2012;144:896-906)

Earn CME credits at

http://cme.ctsnetjournals.org

Survivors of the Norwood procedure for hypoplastic left heart syndrome (HLHS) and other single right ventricle

\footnotetext{
From the Children's Hospital of Wisconsin and Medical College of Wisconsin, ${ }^{\text {a }}$ Milwaukee, Wis; New England Research Institutes, ' Watertown, Mass; Children's Hospital of Philadelphia, ${ }^{\mathrm{c}}$ Philadelphia, Pa; Medical University of South Carolina, ${ }^{\mathrm{d}}$ Charleston, SC; Emory University, ${ }^{\mathrm{e}}$ Atlanta, Ga; Congenital Heart Institute of Florida, ${ }^{\mathrm{f}}$ St Petersburg, Fla; Cincinnati Children's Medical Center, ${ }^{\mathrm{g}}$ Cincinnati, Ohio; Duke University, ${ }^{\text {h }}$ Durham, NC; North Carolina Consortium: National Heart, Lung, and Blood Institute, ${ }^{\mathrm{i}}$ Bethesda, Md; Children's Hospital Boston, ${ }^{\mathrm{j}}$ Boston, Mass; Children's Hospital Los Angeles, ${ }^{\mathrm{k}}$ Los Angeles, Calif; East Carolina University, ${ }^{1}$ Greenville, NC; Primary Children's Medical Center and the University of Utah, ${ }^{\mathrm{m}}$ Salt Lake City, Utah; University of Michigan Medical School, ${ }^{\mathrm{n}}$ Ann Arbor, Mich; Hospital for Sick Children, ${ }^{\circ}$ Toronto, Ontario, Canada; and Columbia University, ${ }^{\mathrm{p}}$ New York, NY.

Supported by Grants HL068269, HL068270, HL068279, HL068281, HL068285, HL068288, HL068290, HL068292, and HL085057 from the National Heart, Lung, and Blood Institute. This work is solely the responsibility of the authors and does not necessarily represent the official views of the National Heart, Lung, and Blood Institute.
}

anomalies are left with the combination of an inefficient parallel circulation with volume load to the systemic ventricle, potential inferior pumping capability of a systemic right ventricle, and risk of compromise of the systemic to pulmonary artery shunt. These factors expose patients to a heightened risk for circulatory collapse. This inherently fragile physiology persists to the stage II procedure when

Disclosures: Authors have nothing to disclose with regard to commercial support. Kerstin R. Allen's current affiliation is Infinity Pharmaceuticals, Boston, Mass; Sarah Tabbutt's current affiliation is University of California San Francisco, San Francisco, Calif; Peter J. Gruber's current affiliation is Primary Children's Medical Center and University of Utah, Salt Lake City, Utah; David S. Cooper's and Pirooz Egthesady's current affiliation is Cincinnati Children's Medical Center, Cincinnati, Ohio.

Pediatric Heart Network Investigators are listed in Appendix 1.

Received for publication Nov 6, 2011; revisions received March 19, 2012; accepted for publication May 9, 2012; available ahead of print July 16, 2012.

Address for reprints: Nancy S. Ghanayem, MD, Medical College of Wisconsin, Children's Hospital of Wisconsin, Pediatrics, 9000 West Wisconsin Ave, PO Box 1997, Milwaukee, WI 53226 (E-mail: nancyg@mcw.edu). $0022-5223 / \$ 36.00$

Copyright (C) 2012 by The American Association for Thoracic Surgery doi: $10.1016 /$ j.jtcvs.2012.05.020 

Abbreviations and Acronyms
AVVR = atrioventricular valve regurgitation
BSA = body surface area
CPR = cardiopulmonary resuscitation
DHCA $=$ deep hypothermic circulatory arrest
ECMO = extracorporeal membrane oxygenation
HLHS = hypoplastic left heart syndrome
MBTS = modified Blalock-Taussig shunt
OR = odds ratio
RVEDV = right ventricular end-diastolic volume
$\mathrm{RVEF}=$ right ventricular ejection fraction
RVESV = right ventricular end-systolic volume
RVPAS $=$ right ventricle-to-pulmonary artery shunt
SVR $=$ Single Ventricle Reconstruction

the parallel circulation is eliminated through takedown of the systemic to pulmonary artery shunt and creation of a cavopulmonary connection. Mortality postdischarge after the Norwood hospitalization and before the stage II procedure (interstage period) is reported to be $2 \%$ to $20 \% .^{1-4}$

Specific risks associated with interstage mortality identified in various investigations include a diminutive ascending aorta as seen in aortic atresia, the presence of a restrictive atrial communication, postoperative arch obstruction, obstructed shunt flow, pulmonary artery distortion, and atrioventricular valve regurgitation (AVVR). ${ }^{5,6}$ Age at surgery, postoperative arrhythmias, airway complications, feeding difficulties, and noncardiac disease processes such as gastroenteritis or upper respiratory infection also have been implicated. ${ }^{3,4}$ Compared with the right ventricle-to-pulmonary artery shunt (RVPAS), higher interstage mortality has been reported for the modified Blalock-Taussig shunt (MBTS).,

The National Heart, Lung, and Blood Institute-sponsored Pediatric Heart Network Single Ventricle Reconstruction (SVR) trial includes the largest prospective cohort of infants with HLHS or related single right ventricle anomalies with longitudinal follow-up after the Norwood procedure. The primary results of the SVR trial demonstrated improved transplant-free survival at 12 months in those randomized to receive an RVPAS at the Norwood procedure compared with those randomized to the MBTS. Although interstage survival was not specifically reported, the highest incidence of transplant or death occurred between 30 days after the Norwood procedure and the stage II procedure. ${ }^{9}$

The goal of this analysis was to determine anatomic, surgical, and additional patient-related risk factors for interstage mortality postdischarge after the Norwood procedure and before the stage II procedure in this unique cohort. We specifically hypothesized that infants palliated with an
MBTS would be at increased risk of interstage death compared with those palliated with an RVPAS.

\section{MATERIALS AND METHODS}

The Pediatric Heart Network SVR trial compared outcomes between subjects randomized to RVPAS and subjects randomized to MBTS at the time of the Norwood procedure. Details of the trial design have been reported. ${ }^{10}$ The institutional review board or research ethics board at each participating center approved the study protocol, and written informed consent was obtained from parents before trial enrollment.

\section{Study Sample}

Subjects randomized in the multicenter SVR trial who survived to discharge from the hospital after the Norwood procedure are included in this analysis. Twenty-two subjects surviving the Norwood procedure, but not discharged before the stage II procedure, were excluded from the primary analysis because of limitations in distinguishing Norwood operative mortality from interstage mortality for subjects with planned inpatient care to stage II procedure. Two subjects whose dates of stage II procedure could not be determined and 2 subjects whose stage II procedures were performed uncharacteristically late (ie, $>14$ months of age) were excluded from the primary analysis.

\section{Study Design and Measurements}

Shunt type was defined for this analysis as the shunt in place at the end of the Norwood procedure. The surgeon had the option to modify the shunt if anatomy was encountered that made the randomized shunt assignment not feasible. Other than random assignment of shunt, all participants were managed according to the standard practices at their clinical centers. A list of all variables that were recorded and analyzed is included in Appendix Table 2. In brief, before the Norwood procedure, a detailed preoperative medical history was recorded, including demographics, patient characteristics, and anatomic diagnosis. Operative variables included shunt type, pharmacologic strategies, perfusion method, and additional cardiac operations. The perfusion method during circulatory support was classified into 1 of 3 categories: deep hypothermic circulatory arrest (DHCA), regional cerebral perfusion with DHCA time of 10 minutes or less, or regional cerebral perfusion with DHCA time greater than 10 minutes. Postoperative data recorded for the Norwood hospitalization included procedures, serious adverse events such as cardiopulmonary resuscitation (CPR) and use of extracorporeal membrane oxygenation (ECMO), number of previously described complications, ${ }^{11}$ hospital length of stay, and feeding methods at discharge after the Norwood procedure.

Echocardiograms were obtained before and after the Norwood procedure. The echocardiograms were interpreted centrally at a core laboratory (Medical College of Wisconsin) to assess the degree of AVVR (none/mild vs moderate/severe), to measure right ventricular end-systolic volume (RVESV) and right ventricular end-diastolic volume (RVEDV), and to determine fractional area change and right ventricular ejection fraction (RVEF). The primary measure of right ventricular contractility used in the multivariable model was right ventricular fractional area change, because the other measures of systolic function including RVEF, RVESV, and RVEDV could not be obtained for $23 \%$ of the subjects. In the 330 subjects for whom both measurements were available, there was a high degree of correlation $(R=0.89)$ between the RVEF and the right ventricular fractional area change.

A subgroup of subjects consented for evaluation by a geneticist. Genetic evaluations performed for clinical indications were also recorded. Subjects were classified as to whether a specific genetic syndrome was identified and whether "other abnormalities" (ie, not identified with a syndrome) were present.

Socioeconomic status at the time of randomization was assigned using a US census-based score derived from 6 measures based on income, housing, and occupational-related features of the subject's census block tract, as 
TABLE 1. Associations of interstage death, site adjusted

\begin{tabular}{|c|c|c|c|c|c|c|c|}
\hline \multirow[b]{2}{*}{ Variables } & \multirow[b]{2}{*}{$\mathbf{n}$} & \multirow[b]{2}{*}{ Responses } & \multirow{2}{*}{$\begin{array}{c}\text { Interstage survivals } \\
\quad(\mathbf{N}=\mathbf{3 7 6})\end{array}$} & \multirow{2}{*}{$\begin{array}{l}\text { Interstage deaths } \\
\qquad(\mathbf{N}=\mathbf{5 0})\end{array}$} & \multirow[b]{2}{*}{$d f$} & \multicolumn{2}{|c|}{ Site adjusted } \\
\hline & & & & & & OR & $\boldsymbol{P}$ \\
\hline Site & 426 & - & - & - & 14 & & \\
\hline \multirow[t]{3}{*}{ Shunt } & 426 & & 376 & 50 & 1 & & $<.001$ \\
\hline & & RVPAS & $212(56)$ & $13(26)$ & & & \\
\hline & & MBTS & $164(44)$ & $37(74)$ & & 3.44 & \\
\hline \multicolumn{8}{|l|}{ Demographic characteristics } \\
\hline \multirow[t]{3}{*}{ Hispanic } & 421 & & 371 & 50 & 1 & & .07 \\
\hline & & No & $305(82)$ & $33(66)$ & & - & \\
\hline & & Yes & $66(18)$ & $17(34)$ & & 1.99 & \\
\hline \multicolumn{8}{|l|}{ US census $\%$ below poverty level } \\
\hline \multirow[t]{4}{*}{ Tertiles } & 409 & - & 364 & 45 & 2 & & .006 \\
\hline & - & $<5.42 \%$ & $131(36)$ & $5(11)$ & - & 0.38 & \\
\hline & - & $5.42 \%-13 \%$ & $113(31)$ & $23(51)$ & - & 1.73 & \\
\hline & - & $\geq 13 \%$ & $120(33)$ & $17(38)$ & - & - & \\
\hline US census socioeconomic score & 409 & & $0.32 \pm 5.1$ & $-1.4 \pm 4.4$ & 1 & 0.95 & .13 \\
\hline \multicolumn{8}{|l|}{ Baseline characteristics } \\
\hline Gestational age (wk) & 426 & & $38.3 \pm 1.5$ & $37.7 \pm 1.9$ & 1 & 0.80 & .02 \\
\hline \multirow[t]{3}{*}{ Preterm (gestational age < $37 \mathrm{wk}$ ) } & 426 & & 376 & 50 & 1 & & .01 \\
\hline & & $\geq 37$ wk & $344(91)$ & $40(80)$ & & - & \\
\hline & & $<37$ wk & $32(9)$ & $10(20)$ & & 2.81 & \\
\hline Birth weight $(\mathrm{kg})$ & 426 & & $3.2(0.5)$ & $3.0(0.5)$ & 1 & 0.57 & .05 \\
\hline \multirow[t]{3}{*}{$\mathrm{AA} / \mathrm{MA}$} & 426 & & 376 & 50 & 1 & & .20 \\
\hline & & No & $235(62)$ & $26(52)$ & & - & \\
\hline & & Yes & $141(38)$ & $24(48)$ & & 1.49 & \\
\hline \multicolumn{8}{|l|}{ Norwood hospitalization } \\
\hline Age at Norwood (d) & 426 & & $5.6 \pm 3.7$ & $6.5 \pm 5.1$ & 1 & 1.06 & .11 \\
\hline Norwood length of stay (d) & 426 & & $28.9 \pm 19.0$ & $36.2 \pm 33.3$ & 1 & 1.01 & .03 \\
\hline Perfusion strategy & 422 & & 373 & 49 & 2 & & .19 \\
\hline DHCA only & & & $211(57)$ & $28(57)$ & & 0.34 & \\
\hline $\mathrm{RCP}$ only or RCP/DHCA time $\leq 10 \mathrm{~min}$ & & & $91(24)$ & $8(16)$ & & 0.38 & \\
\hline $\mathrm{RCP}$ and DHCA time $>10 \mathrm{~min}$ & & & $71(19)$ & $13(27)$ & & - & \\
\hline \multicolumn{8}{|l|}{ Complications and serious adverse events during } \\
\hline \multicolumn{8}{|l|}{ Norwood hospitalization } \\
\hline No. of complications post-Norwood & 426 & & $2.08 \pm 2.1$ & $3.58 \pm 3.4$ & 1 & 1.22 & $<.001$ \\
\hline No. of medications at discharge & 426 & & $4.9 \pm 1.7$ & $5.6 \pm 2.2$ & 1 & 1.15 & .098 \\
\hline Feeding status at discharge post-Norwood & & & & & & & \\
\hline Any oral feeding & 426 & & 376 & 50 & 1 & & $<.001$ \\
\hline & & No & $71(19)$ & $20(40)$ & & - & \\
\hline & & Yes & $305(81)$ & $30(60)$ & & 0.28 & \\
\hline Feeding category ( $4 \mathrm{df})$ & 426 & & 376 & 50 & 4 & & $<.001$ \\
\hline No oral, $G$ or GJ tube & & & $47(13)$ & $8(16)$ & & 1.68 & \\
\hline No oral, NG or NJ tube & & & $24(6)$ & $12(24)$ & & 8.40 & \\
\hline Oral and $\mathrm{G}$ or $\mathrm{GJ}$ tube & & & $19(5)$ & $2(4)$ & & 1.52 & \\
\hline Oral and $\mathrm{NG}$ or $\mathrm{NJ}$ tube & & & $159(42)$ & $15(30)$ & & 0.88 & \\
\hline Only oral & & & $127(34)$ & $13(26)$ & & - & \\
\hline Echocardiography pre-Norwood & & & & & & & \\
\hline AVVR & 417 & & 370 & 47 & 1 & & .004 \\
\hline & & None/mild & $333(90)$ & $35(74)$ & & - & \\
\hline & & Moderate/severe & $37(10)$ & $12(26)$ & & 3.15 & \\
\hline $\begin{array}{l}\text { Ascending aorta diameter (R301), } \mathrm{cm} \\
\text { pre-Norwood }\end{array}$ & 414 & & & & & & \\
\hline Median cutoff & 414 & & 368 & 46 & 1 & & .008 \\
\hline & & $<0.3 \mathrm{~cm}$ & $172(47)$ & $30(65)$ & & 2.44 & \\
\hline & & $\geq 0.3 \mathrm{~cm}$ & $196(53)$ & $16(35)$ & & - & \\
\hline
\end{tabular}




\begin{tabular}{|c|c|c|c|c|c|c|c|}
\hline \multirow[b]{2}{*}{ Variables } & \multirow[b]{2}{*}{$\mathbf{n}$} & \multirow[b]{2}{*}{ Responses } & \multirow{2}{*}{$\begin{array}{l}\text { Interstage survivals } \\
\qquad(\mathbf{N}=\mathbf{3 7 6})\end{array}$} & \multirow{2}{*}{$\begin{array}{l}\text { Interstage deaths } \\
\quad(\mathbf{N}=\mathbf{5 0})\end{array}$} & \multirow[b]{2}{*}{$d f$} & \multicolumn{2}{|c|}{ Site adjusted } \\
\hline & & & & & & OR & $\boldsymbol{P}$ \\
\hline \multicolumn{8}{|l|}{ Echocardiography post-Norwood } \\
\hline $\mathrm{RV}$ end-diastolic volume/BSA ${ }^{1.3}\left(\mathrm{~mL} / \mathrm{m}^{2.6}\right)$ & 330 & & $91.2 \pm 25.2$ & $98.3 \pm 32.8$ & 1 & 1.01 & .14 \\
\hline $\mathrm{RV}$ end-systolic volume/BSA ${ }^{1.3}\left(\mathrm{~mL} / \mathrm{m}^{2.6}\right)$ & 330 & & $48.7 \pm 17.0$ & $56.6 \pm 23.2$ & 1 & 1.02 & .03 \\
\hline RVEF (\%) & 330 & & $47.3 \pm 8.0$ & $43.2 \pm 7.3$ & 1 & 0.94 & .01 \\
\hline RV fractional area change $(\%)$ & 409 & & $37.0 \pm 7.7$ & $34.9 \pm 6.8$ & 1 & 0.97 & .12 \\
\hline \multirow[t]{3}{*}{ AVVR grade } & 423 & & 374 & 49 & 1 & & .06 \\
\hline & & None/mild & $297(80)$ & $32(65)$ & & - & \\
\hline & & Moderate/severe & $77(20)$ & $17(35)$ & & 1.87 & \\
\hline \multirow[t]{3}{*}{ Reversal of pulmonary vein flow } & 384 & & 337 & 47 & 1 & & .18 \\
\hline & & No & $285(85)$ & $44(94)$ & & - & \\
\hline & & Yes & $52(15)$ & $3(5)$ & & 0.46 & \\
\hline \multicolumn{8}{|l|}{ Interaction } \\
\hline \multirow{4}{*}{$\begin{array}{l}\text { Atrioventricular valve insufficiency by shunt } \\
\text { None/mild }\end{array}$} & & & & & 1 & & .009 \\
\hline & & & & & & & \\
\hline & & MBTS & $126(82)$ & $27(18)$ & & 6.71 & $<.001$ \\
\hline & & RVPAS & $171(97)$ & $5(3)$ & & & \\
\hline \multicolumn{8}{|l|}{ Moderate/severe } \\
\hline & & MBTS & $37(80)$ & $9(20)$ & & 1.04 & .94 \\
\hline & & RVPAS & $40(83)$ & $8(17)$ & & & \\
\hline
\end{tabular}

Analyses were performed using logistic regression. Frequency and percent are provided for categoric variables; mean and standard deviations are presented for continuous variables. Firth's adjustment was used if the model fit was questionable. Discharge feeding categories were excluded from the model in favor of any oral feeding at discharge. Only associations with a $P<.20$ are included in the table. For the interaction term, the ORs and $P$ values of shunt type by atrioventricular valve insufficiency are provided. $d f$, Degrees of freedom; $O R$, odds ratio; $R V P A S$, right ventricle-to-pulmonary artery shunt; $M B T S$, modified Blalock-Taussig shunt; $A A / M A$, aortic atresia/mitral atresia; $D H C A$, deep hypothermic circulatory arrest; $R C P$, regional cerebral perfusion; $G$, gastrostomy, $G J$, gastric-jejunal; $N G$, nasogastric; $N J$, nasojejunal; $A V V R$, atrioventricular valve repair; $R V$, right ventricle; $B S A$, body surface area; $R V E F$, right ventricular ejection fraction.

well as a score measuring the percent below the poverty level in the subject's census block tract. ${ }^{12}$

\section{Statistical Methods}

Descriptive statistics presented include median with interquartile range for skewed variables, mean and standard deviation for other continuous variables, and frequency with percentage for categoric variables. Tertiles of continuous measures were fit to determine whether the association between predictor and outcome was nonlinear. Dichotomies were also explored.

Univariate logistic regression and logistic regression adjusted for site were used to obtain initial estimates of association between interstage survival and each candidate predictor. Predictors significant at $P$ less than .20 at the univariate or site-adjusted level were included in the multivariable modeling. Multivariable models were developed using stepwise logistic regression with bootstrap bagging 1000 samples to determine the reliability of each individual predictor. The small number of events made the bootstrapping procedure unstable when site (14 degrees of freedom) was a candidate predictor; thus, the annual center volume of screened patients with a single right ventricle and planned Norwood procedure was included as a surrogate for site in bootstrapping models. A predictor was retained in the final site-adjusted multivariable model if bootstrapping reliability was greater than $45 \%$ and its $P$ value was less than .05 .

To determine whether some prespecified factors had differential associations dependent on shunt type, interaction terms were explored. Specifically, interactions of shunt type with birth weight ( $<2.5 \mathrm{vs} \geq 2.5 \mathrm{~kg}$ ), low gestational age ( $<37$ weeks), ethnicity, obstructed pulmonary venous return, presence of aortic atresia, pre-Norwood and post-Norwood AVVR, and ECMO or CPR during the Norwood hospitalization were examined for their association with interstage death or transplant. After the multivariable model main effects were determined, the significant interactions were added and retained if significant at a $P$ value less than .05 .
In an exploratory analysis, the multivariable model was developed using the same approach, but after imputing missing values of RVEF, RVESV indexed to body surface area (BSA) ${ }^{1.3}$, and RVEDV indexed to BSA ${ }^{1.3}$. Simple regression imputation was used for RVEF, which had $23 \%$ of the data missing at random. Right ventricular fractional area change was used to predict RVEF. For 17 subjects (4\%) who were missing both measurements and for subjects missing RVESV or RVEDV, mean imputation was used. These imputed predictors were included in the model selection process. All analyses were conducted using SAS version 9.2 (SAS Institute, Inc, Cary, NC)

\section{RESULTS}

\section{Study Sample}

Of the 549 subjects who were randomized in the SVR trial and underwent the Norwood procedure, 97 died (88) or underwent heart transplantation (9) during the Norwood hospitalization, 22 remained as inpatients until the stage II procedure, and 430 were discharged before the stage II procedure (Figure 1). The 22 subjects who survived the Norwood procedure and were not discharged before the stage II procedure differed from those who were discharged before the stage II procedure in that hospitalized subjects had a higher rate of ECMO, CPR, moderate or greater AVVR, and postoperative complications (Appendix Table 3). Four subjects discharged were excluded from the analysis because of an uncharacteristically late stage II procedure $(\mathrm{n}=2)$ or unknown timing of the stage II procedure $(\mathrm{n}=2)$. The remaining 426 subjects were 


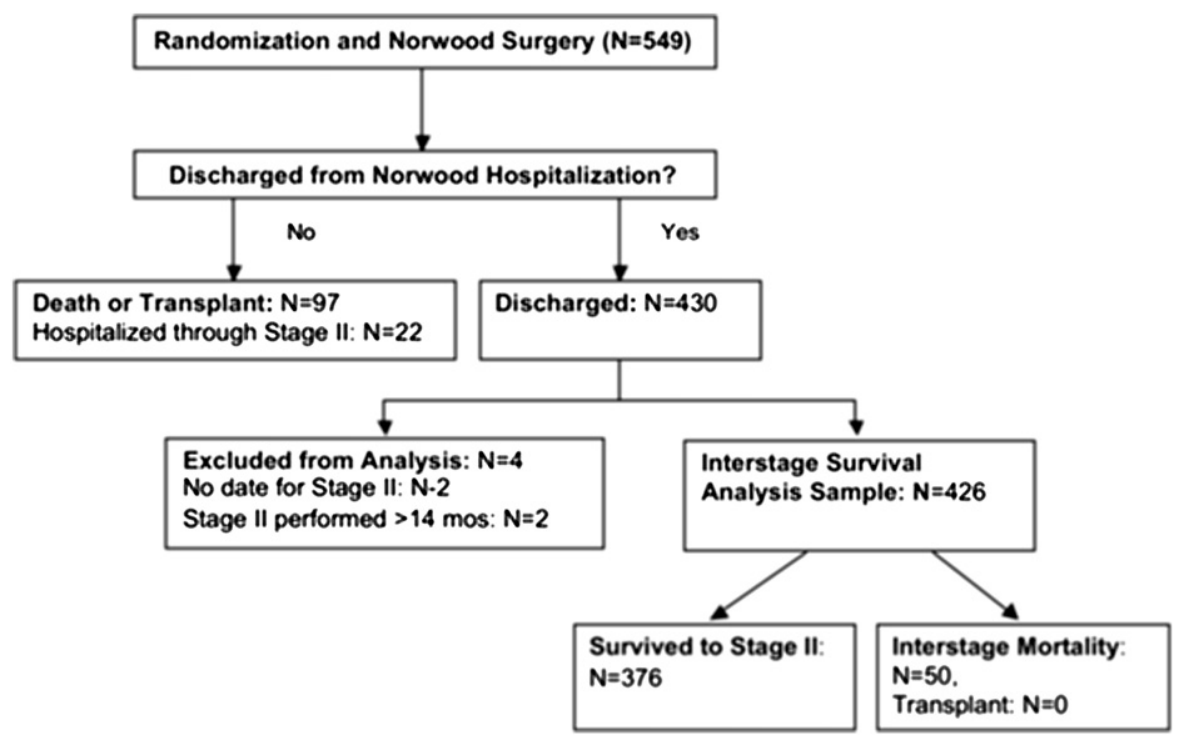

FIGURE 1. Subject participation status from randomization through the interstage period. A total of 430 subjects were discharged after the Norwood procedure. Four of these subjects were excluded because of an unusually late or missing date of the stage II procedure.

discharged after the Norwood procedure and formed the analytic cohort. No subject discharged after the Norwood procedure underwent heart transplantation before the stage II procedure.

\section{Interstage Survival}

Of the 426 interstage subjects, $376(88 \%)$ survived to the stage II procedure. Interstage survival was higher in subjects who received the RVPAS $(212 / 225 ; 94 \%)$ compared

TABLE 2. Multivariable model of predictors of interstage mortality with site adjustment: $N=399$ (adjusted $\left.R^{2}=0.35\right)$

\begin{tabular}{|c|c|c|c|c|}
\hline \multirow[b]{2}{*}{ Predictor } & \multicolumn{2}{|c|}{ Died/heart transplant? } & \multirow{2}{*}{$\begin{array}{c}\text { Odds ratio } \\
(95 \% \text { CI })\end{array}$} & \multirow{2}{*}{$\begin{array}{c}\text { Model } \\
P \text { value }\end{array}$} \\
\hline & No & Yes & & \\
\hline Site & - & - & - & .823 \\
\hline AVVR grade by shunt & & & - & .03 \\
\hline \multicolumn{5}{|l|}{ None/mild } \\
\hline MBTS & $117(84)$ & $23(16)$ & $9.7(3.1-30.3)$ & Contrast $<.001$ \\
\hline RVPAS & $165(97)$ & $5(2.9)$ & - & \\
\hline \multicolumn{5}{|l|}{ Moderate/severe } \\
\hline MBTS & $33(79)$ & $9(21)$ & $1.4(0.4-5.0)$ & Contrast .57 \\
\hline RVPAS & $39(83)$ & $8(17)$ & & \\
\hline \multicolumn{5}{|l|}{ Low gestational age $(<37 \mathrm{wk})$} \\
\hline Yes & $30(75)$ & $10(25)$ & $3.9(1.4-10.8)$ & .008 \\
\hline No & $324(90)$ & $35(10)$ & & \\
\hline \multicolumn{5}{|l|}{ Hispanic } \\
\hline Yes & $63(79)$ & $17(21)$ & $2.6(1.1-6.5)$ & .04 \\
\hline No & $291(91)$ & $28(8.7)$ & & \\
\hline \multicolumn{5}{|l|}{ AA/MA } \\
\hline Yes & $134(85)$ & $23(15)$ & $2.3(1.1-5.0)$ & .03 \\
\hline No & $220(91)$ & $22(9.1)$ & & \\
\hline \multicolumn{5}{|l|}{ No. of complications post-Norwood and predischarge } \\
\hline Mean \pm SD & $2.0 \pm 2.0$ & $3.2 \pm 3.3$ & $1.2(1.1-1.4)$ & .006 \\
\hline US Census percentage below poverty level tertiles & & & & .003 \\
\hline$<5.42$ & $128(96)$ & $5(4)$ & $0.38(0.12-1.3)$ & $.15(0.05-0.48)^{*}$ \\
\hline $5.42-13.0$ & $109(83)$ & $23(17)$ & $2.5(1.02-6.0)$ & - \\
\hline$\geq 13.0$ & $117(87)$ & $17(13)$ & - & \\
\hline
\end{tabular}

Site 19 was excluded from this analysis because all 3 subjects from this site survived and render the model unstable. $C I$, Confidence interval; $A V V R$, atrioventricular valve repair; MBTS, modified Blalock-Taussig shunt; RVPAS, right ventricle-to-pulmonary artery shunt; $A A / M A$, aortic atresia/mitral atresia; $S D$, standard deviation. *Odds of mortality/transplant among subjects in the $<5.42$ tertile compared with subjects in the 5.42-13.0 tertile. 


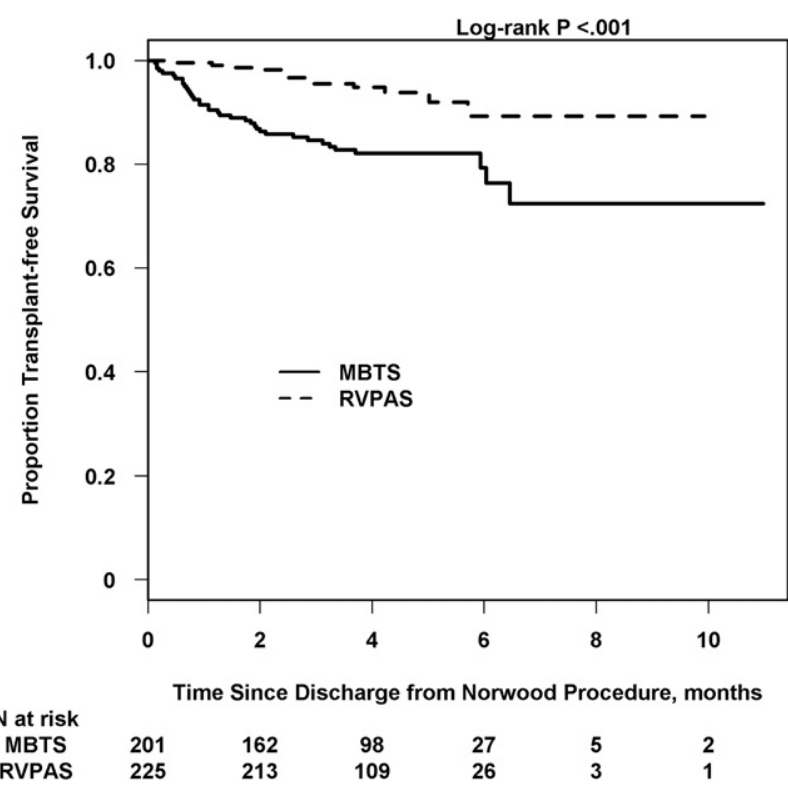

FIGURE 2. Kaplan-Meier plot of interstage survival by shunt type: Interstage survival, defined as percentage alive postdischarge after the Norwood procedure and before the stage II surgery, was significantly better for subjects with an RVPAS than for subjects with an MBTS. MBTS, Modified Blalock-Taussig shunt; RVPAS, right ventricle-to-pulmonary artery shunt.

with those who received the MBTS $(164 / 201 ; 82 \%)$. The odds ratio (OR) for interstage mortality for the MBTS versus the RVPAS was 3.4 (95\% confidence interval, 1.8-6.6; $P<.001$ ) (Figure 2). Of the subjects who died during the interstage period, the mean time to death postdischarge after the Norwood procedure was earlier in the MBTS group (1.7 \pm 1.6 months vs $2.8 \pm 1.5$ months postdischarge after the Norwood procedure, $P<.001$ ), with a mean age at death $3.0 \pm 2.0$ months in the MBTS group and $4.3 \pm 1.7$ months in the RVPAS group $(P=.01)$. The stage II procedure was performed at similar ages for the 2 shunt types $(5.5 \pm 1.7$ months vs $5.3 \pm 1.6$ months, $P=.34$ ).

\section{Risk Factors for Interstage Mortality}

Univariate analysis. Univariate analysis was performed to assess the association of each potential risk factor with interstage mortality (Table 1). In addition to the MBTS, younger gestational age, census tract block with $5.4 \%$ to $13 \%$ of inhabitants below federal poverty level, ascending aorta diameter less than $3 \mathrm{~mm}$, longer Norwood hospital length of stay (median, 25; interquartile range, 17 to 44 days vs 23 days; interquartile range, 16-36), greater number of postoperative complications, and failure to feed orally before hospital discharge were associated with interstage mortality. The risk of interstage mortality was also higher in subjects without any oral feeding with a nasal enteral tube compared with a gastrostomy tube (OR, 5.0; 95\% confidence interval, $1.5-17.1 ; P=.01)$. Moderate to severe postoperative AVVR, lower RVEF, and greater RVESV indexed to
BSA $^{1.3}$ measured on post-Norwood echocardiograms (performed $15 \pm 10$ days after the Norwood procedure) were each associated with interstage mortality. Site was not a significant predictor of interstage mortality $(P=.16)$. Genetic syndrome and nonsyndromic comorbidities also were not associated with interstage mortality.

Of the prespecified factors, only the interaction of shunt type and postoperative AVVR was significantly associated with interstage mortality $(P=.009)$. After adjustment for site, the influence of shunt type varied with degree of AVVR. In subjects with postoperative none/mild AVVR, interstage mortality was significantly higher for the MBTS group (MBTS 18\% vs RVPAS 3\%; $P<.001$; OR, 6.7). However, for subjects with postoperative moderate/severe AVVR, the overall rate of interstage mortality was similar between the shunt types (MBTS $20 \%$ vs RVPAS $17 \%$; $P=.94$; OR, 1.0).

Multivariable analysis. Independent predictors of interstage mortality with adjustment for site determined through multivariable modeling (adjusted $R^{2}=0.35$ ) included gestational age less than 37 weeks (OR, 3.9; $P=.008)$, Hispanic ethnicity (OR, 2.6; $P=.04)$, census block poverty level $(P=.003)$, presence of aortic and mitral atresia (OR, 2.3; $P=.03$ ), MBTS in subjects with postoperative none/mild AVVR (OR, 9.7; $P<.001)$, and greater number of post-Norwood complications (OR, 1.2, per complication; $P=.006)$. With respect to census block poverty levels, subjects in communities with $5.4 \%$ to $13 \%$ poverty had a greater risk of interstage mortality compared with subjects in the more affluent communities (OR, 6.7) and the poorest communities (OR, 2.5) (Table 2). The exploratory analysis that included imputed missing values of RVEF, RVESV, RVEDV, and RV fractional area change showed that these potential predictors were not independent risk factors of interstage mortality.

\section{DISCUSSION}

This is the first multicenter prospective report of interstage mortality for infants with HLHS and other single right ventricle anomalies undergoing staged repair. The overall interstage mortality rate of $12 \%$ from this large cohort is similar to that of multiple prior single-center case series. ${ }^{1,3,4,7,8,13}$

Subjects who had an MBTS were at higher risk for interstage mortality than those with RVPAS. With pulmonary blood flow occurring only during systole after palliation with the RVPAS, a higher diastolic pressure and lower pulmonary to systemic flow ratio has been observed. ${ }^{14,15}$ Although we are unable to determine the mechanisms of interstage death in this population, it is possible that the higher diastolic pressure associated with RVPAS contributes to improved coronary and systemic perfusion, providing advantageous hemodynamic stability during periods of stress such as illness or feeding difficulties. Patients with an MBTS may have a higher risk for acute shunt thrombosis; 
however, the incidence of shunt thrombosis as a cause for death was not examined in this analysis.

Although only shunt type was randomized in the SVR trial, the sample size and prospective data collection allowed for evaluation of other potential predictors of interstage mortality. Previous reports have implicated anatomic diagnosis, residual or recurrent lesions, arrhythmias, subject specific characteristics, acquired illness, and, more recently, shunt type as risk factors for interstage death. ${ }^{1,3-8,13}$ Although Jonas and colleagues ${ }^{5}$ found the combination of aortic atresia with mitral stenosis to be associated with interstage mortality for infants with HLHS, ${ }^{5}$ other investigators reviewing single-center series have not found this anatomic variant to be a risk factor. ${ }^{4,16}$ In the SVR cohort, only aortic atresia combined with mitral atresia was independently associated with interstage mortality. Aortic atresia with mitral stenosis was not associated with worsened interstage survival for the cohort as a whole or for either shunt group.

Single-center comparisons of subjects with the RVPAS versus the MBTS have reported no observable differences in myocardial performance and ventricular volumes before the stage II procedure. ${ }^{17,18}$ Although measurable differences in RVEF and RVESV indexed for BSA were observed between shunt types before discharge after the Norwood procedure, these echocardiographic findings were not independent risk factors for interstage mortality. Previous studies have identified postoperative moderate/ severe AVVR as a risk factor for interstage mortality. In the current analysis, shunt type was a predictor of interstage mortality when there was mild or no postoperative AVVR. However, when postoperative AVVR was moderate or greater, there was no selective benefit of the RVPAS and both shunt groups had higher mortality rates compared with subjects with mild or no AVVR and an RVPAS. These data suggest that the higher interstage mortality risk for the MBTS is not a consequence of greater AVVR. Moderate to severe AVVR does increase the risk of interstage mortality, possibly secondary to the additional volume load and ineffective ventricular output that can be exacerbated by conditions that elevate systemic vascular resistance.

We found that gestational age less than 37 weeks was an independent risk factor for interstage mortality. Given the high correlation of gestational age with birth weight, it is not surprising that birth weight was not found to be a separate independent risk factor. In a series comparing outcomes after cardiac surgery for term and preterm infants, complications of prematurity and postoperative mortality were common in preterm infants, illustrating the added vulnerability of preterm subjects. ${ }^{19}$ Other studies have identified extracardiac anomalies as a risk factor for mortality in subjects with HLHS. ${ }^{20,21}$ Extracardiac anomalies were not associated with increased risk in our cohort, but this may be confounded by a greater tendency for subjects with extracardiac malformations to die before hospital discharge. Furthermore, although use of an RVPAS has been advocated in the presence of high-risk characteristics, ${ }^{13}$ our analysis did not demonstrate a particular protective effect of the RVPAS for preterm or low-birth-weight infants or for infants with extracardiac anomalies. Again, when considering this finding, it is important to consider that inclusion in this cohort required survival of the Norwood procedure and discharge from the hospital. Thus, subjects with these risks may be less likely to survive to hospital discharge after the Norwood procedure. Delivery at term seems to be an important and likely modifiable risk factor. This observation is consistent with a large series in which neonates aged less than 39 weeks with critical congenital heart disease had greater morbidity and interstage mortality than infants delivered at more than 39 weeks. ${ }^{22}$

Having a higher number of postoperative complications correlated with longer length of stay and was an independent risk factor for interstage mortality. Longer length of stay in other series of infants with serious congenital heart disease has been associated with negative outcomes, including early mortality and lower scores on neurodevelopmental testing. ${ }^{23}$

Poor interstage growth velocity and malnutrition are common after the Norwood procedure ${ }^{24,25}$; thus, alternative feeding methods may be necessary to ensure adequate nutritional support. However, the best approach to feeding children after the Norwood procedure remains a challenge and there is wide variation in practice patterns. Univariate analysis showed that the absence of oral feeding before discharge after the Norwood procedure was associated with interstage mortality, particularly if nasogastric tube feedings were used rather than a direct gastrostomy tube. Poor feeding and failure to thrive in infants with congenital heart disease, specifically single ventricle disease, may be secondary to several mechanisms, such as decompensated heart failure, airway abnormalities, or gastrointestinal dysmotility. Thus, inability to feed orally may be a surrogate for added vulnerability in the infant with Norwood physiology. These data suggest that for subjects who require enteral tube feeding with complete absence of oral feeding, discharge with a direct gastrostomy tube may be preferable over a nasal enteral tube. The mechanism for interstage death in those with a nasogastric tube may include aspiration due to stenting of the lower esophageal sphincter, impaired breathing due to nasopharyngeal obstruction, or vagal response from reflux or gagging leading to bradycardia-induced arrhythmias.

Interstage mortality was associated with 2 sociodemographic variables: living in a census block with 5.4\% to $13 \%$ below the poverty level and Hispanic ethnicity. Although the finding that participants in census blocks with lower or higher poverty levels had a lower risk of interstage mortality is not intuitive, it is possible that access to care was more limited in communities with $5.4 \%$ to $13 \%$ 
of residents below the poverty level. Although determining access to care was not within the scope of this study, it may be valuable to identify high-risk families with reduced access to nearby care to develop a support network and optimize interstage surveillance. Home monitoring with daily oxygen saturations and weight measurements, and with increased communication, has been associated with reduced interstage mortality in some series ${ }^{2,4,26}$ and may be of particular value when access to pediatric cardiac care is not readily available. Practices for home monitoring were not standardized in the SVR trial, and its impact on interstage mortality was not evaluated in this analysis.

Although this is the largest prospectively followed cohort of children with HLHS and other single right ventricle anomalies studied for risk factors for interstage mortality, there are limitations of our investigation. There was wide variation in practice throughout the course of this study across the clinical sites, including inpatient management for select patients with complicated post-Norwood hospitalization. Many variables evaluated in this study may be linked, and thus the implications of some practices cannot be defined. Furthermore, some variables deemed important even in the multivariable models may be only surrogates for other unmeasured variables. By adjusting for site and using bootstrapping, we have tried to minimize bias and maximize reliability.

\section{CONCLUSIONS}

We found higher interstage mortality in subjects who received an MBTS. However, RVPAS was only protective for interstage mortality in those subjects with none/mild AVVR after the Norwood procedure. Additional independent risk factors for interstage mortality included gestational age less than 37 weeks, Hispanic ethnicity, census block with $5.4 \%$ to $13 \%$ of inhabitants below poverty level, aortic atresia/mitral atresia, and increased number of postNorwood complications. On the basis of our findings, we recommend avoiding preterm delivery when possible and considering close surveillance of infants discharged after the Norwood procedure with these identified risk factors.

\section{References}

1. Simsic JM, Bradley SM, Stroud MR, Atz AM. Risk factors for interstage death after the Norwood procedure. Pediatr Cardiol. 2005;26:400-3.

2. Ghanayem NS, Tweddell JS, Hoffman GM, Mussatto K, Jaquiss RD. Optimal timing of the second stage of palliation for hypoplastic left heart syndrome facilitated through home monitoring, and the results of early cavopulmonary anastomosis. Cardiol Young. 2006;16(Suppl I):60-5.

3. Hehir DA, Dominguez TE, Ballweg JA, Ravishankar C, Marino BS, Bird GL, et al. Risk factors for interstage death after stage 1 reconstruction of hypoplastic left heart syndrome and variants. J Thorac Cardiovasc Surg. 2008;136:94-9.

4. Furck AK, Uebing A, Hansen JH, Scheewe J, Jung O, Fischer G, et al. Outcome of the Norwood operation in patients with hypoplastic left heart syndrome: a 12-year single-center survey. J Thorac Cardiovasc Surg. 2010;139:359-65.

5. Jonas RA, Hansen DD, Cook N, Wessel D. Anatomic subtype and survival after reconstructive operation for hypoplastic left heart syndrome. J Thorac Cardiovasc Surg. 1994;107:1121-8.
6. Bartram U, Grunenfelder J, Van Praagh R. Causes of death after the modified Norwood procedure: a study of 122 postmortem cases. Ann Thorac Surg. 1997;64:1795-802.

7. Tabbutt S, Dominguez TA, Ravishankar C, Marino BS, Gruber PJ, Wernovsky G, et al. Contemporary comparison of outcomes following use of the right ventricular to pulmonary artery conduit vs the modified Blalock Taussig shunt as part of the modified Norwood procedure. Ann Thorac Surg. 2005;80:1582-90.

8. Cua CL, Thiagarajan RR, Gauvreau K, Lai L, Costello JM, Wessel DL, et al. Early postoperative outcomes in a series of infants with hypoplastic left heart syndrome undergoing stage 1 palliation operation with either modified Blalock-Taussig shunt or right ventricle to pulmonary artery conduit. Pediatr Crit Care Med. 2006; 7:238-44.

9. Ohye RG, Sleeper LA, Mahony L, Newburger JW, Pearson GD, Goldberg CS, et al. Comparison of shunt types in the Norwood procedure for single ventricle lesions. N Engl J Med. 2010;362:1980-92.

10. Ohye RG, Gaynor JW, Ghanayem NS, Goldberg CS, Laussen PC, Frommelt PC, et al. Design and rationale of a randomized trial comparing the Blalock-Taussig and right ventricle-pulmonary artery shunts in the Norwood procedure. J Thorac Cardiovasc Surg. 2008;136:968-75.

11. Virzi L, Pemberton V, Ohye RG, Tabbutt S, Lu M, Atz TC, et al. Reporting adverse events in a surgical trial for complex congenital heart disease: The Pediatric Heart Network experience. J Thorac Cardiovasc Surg. 2011;142:531-7.

12. Singh TP, Gauvreau K, Bastardi HJ, Blume ED, Mayer JE. Socioeconomic position and graft failure in pediatric heart transplant recipients. Circ Heart Fail. 2009;2:160-5.

13. Sano S, Huang SC, Kasahara S, Yoshizumi K, Kotani Y, Ishino K. Risk factors for mortality after the Norwood procedure using the right ventricle to pulmonary artery shunt. Ann Thorac Surg. 2009;87:178-86.

14. Bradley SM, Simsic JM, McQuinn TC, Habib DM, Shirali GS, Atz AM. Hemodynamic status after the Norwood procedure: a comparison of right ventricle-topulmonary artery connection versus modified Blalock-Taussig shunt. Ann Thorac Surg. 2004;78:933-41.

15. Ghanayem NS, Jaquiss RD, Cava JR, Frommelt PC, Mussatto KA, Hoffman GM, et al. Right ventricle-to-pulmonary artery conduit versus Blalock-Taussig shunt: a hemodynamic comparison. Ann Thorac Surg. 2006;82:1603-10.

16. Polimenakos AC, Sathanandam SK, Hussayni TS, El Zein CF, Roberson DA, Ilbawi MN. Hypoplastic left heart syndrome and aortic atresia-mitral stenosis variant. Role of myocardial protection strategy and impact of ventriculocoronary connections after stage 1 palliation. Pediatr Cardiol. 2011;32:929-39.

17. Frommelt PC, Sheridan DC, Mussatto KM, Hoffman GM, Ghanayem NS, Frommelt MA, et al. Effect of shunt type on echocardiographic indices after initial palliation for hypoplastic left heart syndrome: Blalock-Taussig shunt versus right ventricle-pulmonary artery conduit. J Am Soc Echocardiogr. 2007;20:1364-73.

18. Graham EM, Atz AM, Bradley SM, Scheurer MA, Bandisode VM, Laudito A, et al. Does a ventriculotomy have deleterious effects following palliation in the Norwood procedure using a shunt placed from the right ventricle to the pulmonary arteries? Cardiol Young. 2007;17:145-50.

19. Natarajan G, Anne SR, Aggarwal S. Outcomes of congenital heart disease in late pre-term infants: double jeopardy? Acta Paediatr. 2011;100:1104-7.

20. Gaynor JW, Mahle WT, Cohen MI, Ittenbach RF, DeCampli WM, Steven JW, et al. Risk factors for mortality after the Norwood procedure. Eur J Cardiothorac Surg. 2002;22:82-9.

21. Stasik CN, Gelehrter S, Goldberg CS, Bove EL, Devaney EJ, Ohye RG. Current outcomes and risk factors for the Norwood procedure. J Thorac Cardiovasc Surg. 2006;131:412-7.

22. Costello JM, Polito A, Brown DW, McElrath TF, Graham DA, Thiagarajan RR, et al. Delivery before 39 weeks is associated with adverse outcomes in neonates with cardiac disease. Pediatrics. 2010;126:277-84.

23. Newburger JW, Wypij D, Bellinger DC, du Plessis AJ, Kuban KC, Rappaport LA, et al. Length of stay after infant heart surgery is related to cognitive outcome at age 8 years. J Pediatr. 2003;143:67-73.

24. Kelleher DK, Laussen P, Teixeira-Pinto A, Duggan C. Growth and correlates of nutritional status among infants with hypoplastic left heart syndrome (HLHS) after stage 1 Norwood procedure. Nutrition. 2006;22:237-44.

25. Anderson JB, Beekman RH 3rd, Border WL, Kalkwarf HJ, Khoury PR, Uzark K, et al. Lower weight-for-age $\mathrm{z}$ score adversely affects hospital length of stay after the bidirectional Glenn procedure in 100 infants with a single ventricle. J Thorac Cardiovasc Surg. 2009;138:397-404.

26. Ghanayem NS, Hoffman GM, Mussatto KA, Cava JR, Frommelt PC, Rudd NA, et al. Home surveillance program prevents interstage mortality after the Norwood procedure. J Thorac Cardiovasc Surg. 2003;126:1367-77. 


\section{APPENDIX 1. Pediatric Heart Network Investigators}

National Heart, Lung, and Blood Institute: Gail Pearson, Victoria Pemberton, Rae-Ellen Kavey,* Mario Stylianou, Marsha Mathis*

Network Chair: University of Texas Southwestern Medical Center, Lynn Mahony

Data Coordinating Center: New England Research Institutes, Lynn Sleeper (PI), Sharon Tennstedt (PI), Steven Colan, Lisa Virzi,* Patty Connell,* Victoria Muratov, Lisa Wruck,* Minmin Lu, Dianne Gallagher, Anne Devine,* Julie Schonbeck, Thomas Travison,* David F. Teitel

Core Clinical Site Investigators: Children's Hospital Boston, Jane W. Newburger (PI), Peter Laussen, Pedro del Nido, Roger Breitbart, Jami Levine, Ellen McGrath, Carolyn Dunbar-Masterson, John E. Mayer, Jr, Frank Pigula, Emile A. Bacha, Francis Fynn-Thompson; Children's Hospital of New York, Wyman Lai (PI), Beth Printz,* Daphne Hsu,* William Hellenbrand, Ismee Williams, Ashwin Prakash,* Seema Mital,* Ralph Mosca, ${ }^{*}$ Darlene Servedio, ${ }^{*}$ Rozelle Corda, Rosalind Korsin, Mary Nash*; Children's Hospital of Philadelphia, Victoria L. Vetter (PI), Sarah Tabbutt,* J. William Gaynor (Study Co-Chair), Chitra Ravishankar, Thomas Spray, Meryl Cohen, Marisa Nolan, Stephanie Piacentino, Sandra DiLullo,* Nicole Mirarchi; Cincinnati Children's Medical Center, D. Woodrow Benson (PI), Catherine Dent Krawczeski, Lois Bogenschutz, Teresa Barnard, Michelle Hamstra, Rachel Griffiths, Kathryn Hogan, Steven Schwartz,* David Nelson, Pirooz Eghtesady*; North Carolina Consortium: Duke University, East Carolina University, Wake Forest University, Page A. W. Anderson (PI) - deceased, Jennifer Li (PI), Wesley Covitz, Kari Crawford,* Michael Hines, James Jaggers, * Theodore Koutlas, Charlie Sang, Jr, Lori Jo Sutton, Mingfen Xu;

Medical University of South Carolina, J. Philip Saul (PI), Andrew Atz, Girish Shirali, Scott Bradley, Eric Graham, Teresa Atz, Patricia Infinger; Primary Children's Medical Center and the University of Utah, L.

LuAnn Minich (PI), John A. Hawkins, Michael Puchalski, Richard V. Williams, Peter C. Kouretas, Linda M. Lambert, Marian E. Shearrow, Jun A. Porter*; Hospital for Sick Children, Brian McCrindle (PI), Joel Kirsh, Chris Caldarone, Elizabeth Radojewski, Svetlana Khaikin, Susan McIntyre, Nancy Slater; University of Michigan, Caren S. Goldberg (PI), Richard G. Ohye (Study Chair), Cheryl Nowak*; Children's Hospital of Wisconsin and Medical College of Wisconsin, Nancy S. Ghanayem (PI), James S. Tweddell, Kathleen A. Mussatto, Michele A. Frommelt, Peter C. Frommelt, Lisa Young-Borkowski

Auxiliary Sites: Children's Hospital Los Angeles, Alan Lewis (PI), Vaughn Starnes, Nancy Pike; The Congenital Heart Institute of Florida, Jeffrey P. Jacobs (PI), James A. Quintessenza, Paul J. Chai, David S. Cooper, J. Blaine John, James C. Huhta, Tina Merola, Tracey Grifith; Emory University, William Mahle (PI), Kirk Kanter, Joel Bond,* Jeryl Huckaby; Nemours Cardiac Center, Christian Pizarro (PI), Carol Prospero; Julie Simons, Gina Baffa, Wolfgang A. Radtke; University of Texas Southwestern Medical Center, Ilana Zeltzer (PI), Tia Tortoriello,* Deborah McElroy, Deborah Town

Angiography Core Laboratory: Duke University, John Rhodes, J. Curt Fudge

Echocardiography Core Laboratories: Children's Hospital of Wisconsin, Peter Frommelt; Children's Hospital Boston, Gerald Marx

Genetics Core Laboratory: Children's Hospital of Philadelphia, Catherine Stolle

\section{APPENDIX 1. Continued}

Protocol Review Committee: Michael Artman (Chair), Erle Austin, Timothy Feltes, Julie Johnson, Thomas Klitzner, Jeffrey Krischer, G. Paul Matherne

Data and Safety Monitoring Board: John Kugler (Chair), Rae-Ellen Kavey* (Executive Secretary), David J. Driscoll, Mark Galantowicz, Sally A. Hunsberger, Thomas J. Knight, Holly Taylor, Catherine L. Webb*

PI, Principal investigator. *No longer at the institution listed. 


\section{APPENDIX TABLE 2. Candidate predictor list}

\section{Site}

Shunt type

Baseline characteristics

Gestational age (wk)

Preterm (gestational age $<37$ wk)

Birth weight $(\mathrm{kg})$

Low birth weight $(<2500 \mathrm{~g})$

Race (white, black, other)

Hispanic

Anatomic diagnosis (HLHS, single right ventricle with systemic outflow, straddling mitral valve with left ventricle hypoplasia and outflow obstruction, other)

HLHS (yes/no)

Heterotaxy (yes/no)

Aortic atresia/mitral atresia (yes/no)

Aortic atresia/mitral stenosis (yes/no)

Aortic stenosis/mitral stenosis (yes/no)

Obstructed pulmonary venous return (yes/no)

Age at Norwood (d)

US Census Socioeconomic Index Score

US Census \% below poverty level

Norwood hospitalization

Total bypass time (min)

Perfusion strategy during Norwood: DHCA only, RCP only or RCP with DHCA no $>10 \mathrm{~min}, \mathrm{RCP}$ and DHCA time $>10 \mathrm{~min}$ )

ECMO (yes/no)

Ultrafiltration during (yes/no)

Aortic atresia (yes/no)

Steroids (yes/no)

Trasylol (yes/no)

Alpha-blockade (yes/no)

CPR post-Norwood during hospital stay (yes/no)

Oxygen saturation at discharge post-Norwood (yes/no)

Norwood length of stay

No. of unintended cardiovascular procedures

Balloon dilation, stent placement, or surgical revision of the neo-aorta (yes/no)

Pulmonary artery reconstruction (yes/no)

Balloon dilation or stenting of the shunt or branch pulmonary arteries (yes/no)

Shunt revision or crossover (yes/no)

Atrioventricular valve repair (yes/no)

Diaphragm plication (yes/no)

Gastrostomy tube (yes/no)

Pericardial window (yes/no)

Shunt revision (no crossover)

Thoracostomy tube (yes/no)

No. of complications predischarge, post-Norwood

Any serious adverse event (yes/no)

Any oral feeding at discharge (yes/no)

Only oral feeding at discharge (yes/no)

Feeding category (gastrostomy or gastrostomy-jejunal tube, nasal gastric or nasal jejunal tube, only oral)

Feeding category (no oral, G or GJ tube; no oral, NG or NJ tube; oral, G or GJ tube; oral, NG or NJ tube; only oral)

No. of discharge medications

\section{APPENDIX TABLE 2. Continued}

Echocardiography pre-Norwood

RVEDV indexed to $\mathrm{BSA}^{1.3}$

RVESV indexed to BSA ${ }^{1.3}$

RVEF

Atrioventricular valve insufficiency (moderate to severe AVVR) at pre-Norwood

Ascending aorta diameter (mm)

Echocardiography post-Norwood

Echo Nakata Index

Aortic valve insufficiency (not patent, no regurgitation, regurgitation)

Atrioventricular valve insufficiency at post-Norwood (none/mild vs moderate/severe).

Right ventricular end-diastolic volume indexed to $\mathrm{BSA}^{1.3}$

Right ventricular end-systolic volume indexed to $\mathrm{BSA}^{1.3}$

RVEF

Right ventricular percent area change

Reversal of pulmonary vein flow (yes/no)

Genetic evaluations (yes at any visit)

Genetic syndrome (yes/no)

Any nonsyndromic abnormality (yes/no)

Genotype (E3/E3, E4/E4, E2/E3, E2/E4, E3/E4)

Site volume and surgeon Norwood volume

Surgeon Norwood experience, based on all screened subjects (continuous and 4-level categories)

Site volume, based on annual center volume of Norwood procedures (continuous and 4-level categories)

HLHS, Hypoplastic left heart syndrome; $D H C A$, deep hypothermic circulatory arrest $R C P$, regional cerebral perfusion; ECMO, extracorporeal membrane oxygenation; $C P R$, cardiopulmonary resuscitation; $G$, gastrostomy, $G J$, gastric-jejunal; $N G$, nasogastric; $N J$, nasojejunal; $R V E D V$, right ventricular end-diastolic volume; $B S A$, body surface area; $R V E S V$, right ventricular end-systolic volume; $R V E F$, right ventricular ejection fraction; $A V V R$, atrioventricular valve regurgitation. 
APPENDIX TABLE 3. Univariate comparisons of subjects who were discharged after Norwood procedure with those who were not discharged and survived to stage II

\begin{tabular}{|c|c|c|c|}
\hline Characteristic & $\begin{array}{c}\text { Discharged } \\
(\mathbf{N}=\mathbf{4 2 6})\end{array}$ & $\begin{array}{l}\text { Not discharged } \\
\text { and survived } \\
(\mathrm{N}=\mathbf{2 2})\end{array}$ & $\begin{array}{c}P \\
\text { value }\end{array}$ \\
\hline Shunt & & & .52 \\
\hline RVPAS & $225(53)$ & $10(46)$ & \\
\hline MBTS & $201(47)$ & $12(55)$ & \\
\hline \multicolumn{4}{|l|}{ Norwood hospitalization } \\
\hline \multicolumn{4}{|l|}{$\begin{array}{l}\text { Norwood length of } \\
\text { stay (d) }\end{array}$} \\
\hline Median (IQR) & $23(16-36)$ & $115(67-147)$ & $<.001$ \\
\hline \multicolumn{4}{|l|}{ Total bypass time (min) } \\
\hline Median (IQR) & $130.0(101.0-163.0)$ & 152.0 & .03 \\
\hline Placed on ECMO & & & $<.001$ \\
\hline No & $402(94)$ & $13(59)$ & \\
\hline Yes & $24(5.6)$ & $9(41)$ & \\
\hline Ultrafiltration during $\mathrm{CPB}$ & & & .02 \\
\hline No & $161(38)$ & $3(14)$ & \\
\hline Yes & $265(62)$ & $19(86)$ & \\
\hline Steroids & & & .005 \\
\hline No & $40(9.4)$ & $7(32)$ & \\
\hline Yes & $386(91)$ & $15(68)$ & \\
\hline $\begin{array}{l}\text { CPR post-Norwood } \\
\text { during hospital stay }\end{array}$ & & & $<.001$ \\
\hline No & $397(93)$ & $10(45)$ & \\
\hline Yes & $29(6.8)$ & $12(55)$ & \\
\hline $\begin{array}{l}\text { No. of unintended } \\
\text { cardiovascular } \\
\text { procedures }\end{array}$ & & & $<.001$ \\
\hline 0 & $360(85)$ & $12(55)$ & \\
\hline 1 & $56(13)$ & $6(27)$ & \\
\hline$\geq 2$ & $10(2.3)$ & $4(18)$ & \\
\hline $\begin{array}{l}\text { Balloon dilation or stenting } \\
\text { of the shunt or branch } \\
\text { pulmonary arteries }\end{array}$ & & & .02 \\
\hline No & $408(96)$ & $18(82)$ & \\
\hline Yes & $18(4.2)$ & $4(18)$ & \\
\hline Shunt revision or crossover & & & .04 \\
\hline No & $378(89)$ & $16(73)$ & \\
\hline Yes & $48(11)$ & $6(27)$ & \\
\hline $\begin{array}{l}\text { Shunt revision without } \\
\text { crossover }\end{array}$ & & & .002 \\
\hline No & $411(96)$ & $17(77)$ & \\
\hline Yes & $15(3.5)$ & $5(23)$ & \\
\hline PA reconstruction & & & .05 \\
\hline No & $426(100)$ & $21(95)$ & \\
\hline Yes & $0(0.0)$ & $1(4.5)$ & \\
\hline Gastrostomy tube & & & .002 \\
\hline No & $357(84)$ & $12(55)$ & \\
\hline Yes & $69(16)$ & $10(45)$ & \\
\hline Thoracostomy tube & & & .03 \\
\hline No & $404(95)$ & $18(82)$ & \\
\hline Yes & $22(5)$ & $4(18)$ & \\
\hline
\end{tabular}

APPENDIX TABLE 3. Continued

\begin{tabular}{|c|c|c|c|}
\hline Characteristic & $\begin{array}{c}\text { Discharged } \\
(\mathbf{N}=426)\end{array}$ & $\begin{array}{l}\text { Not discharged } \\
\text { and survived } \\
(\mathbf{N}=\mathbf{2 2})\end{array}$ & $\begin{array}{c}P \\
\text { value }\end{array}$ \\
\hline \multicolumn{4}{|l|}{$\begin{array}{l}\text { Complications and } \\
\text { serious adverse events }\end{array}$} \\
\hline \multicolumn{4}{|l|}{ No. of complications } \\
\hline $\begin{array}{l}\text { Median (IQR) } \\
\text { No. of SAEs }\end{array}$ & $2.0(1.0-3.0)$ & $6.0(3.0-15.0)$ & $<.001$ \\
\hline Median (IQR) & $0.0(0.0-0.0)$ & $1.0(0.0-2.0)$ & $<.001$ \\
\hline Any SAE & & & $<.001$ \\
\hline 0 & $362(85)$ & $9(41)$ & \\
\hline$\geq 1$ & $64(15)$ & $13(59)$ & \\
\hline \multicolumn{4}{|l|}{ Feeding at discharge } \\
\hline Any oral feeding? & & & $<.001$ \\
\hline No & $91(21)$ & $18(82)$ & \\
\hline Yes & $335(79)$ & $4(18)$ & \\
\hline Only oral feeding? & & & $<.001$ \\
\hline No & $286(67)$ & $22(100)$ & \\
\hline Yes & $140(33)$ & $0(0)$ & \\
\hline Feeding category ( $3 \mathrm{df})$ & & & $<.001$ \\
\hline Any oral, other tube & $0(0.0)$ & $1(5)$ & \\
\hline Any oral, G or GJ tube & $76(18)$ & $12(55)$ & \\
\hline Any oral, NG or NJ tube & $210(49)$ & $9(41)$ & \\
\hline Only oral & $140(33)$ & $0(0)$ & \\
\hline Feeding category (4 df) & & & $<.001$ \\
\hline No oral, other tube & $0(0)$ & $1(5)$ & \\
\hline No oral, $\mathrm{G}$ or GJ tube & $55(13)$ & $10(45)$ & \\
\hline No oral, NG or NJ tube & $36(8)$ & $7(32)$ & \\
\hline Oral and $\mathrm{G}$ or GJ tube & $21(5)$ & $2(9)$ & \\
\hline Oral and NG or NJ tube & $174(41)$ & $2(9)$ & \\
\hline Only oral & $140(33)$ & $0(0)$ & \\
\hline \multicolumn{4}{|l|}{ Echocardiography } \\
\hline AVVR & & & .04 \\
\hline None/mild & $368(88)$ & $16(73)$ & \\
\hline Moderate/severe & $49(12)$ & $6(27)$ & \\
\hline \multicolumn{4}{|l|}{ post-Norwood } \\
\hline \multicolumn{4}{|l|}{ Akata Index } \\
\hline Median (IQR) & $\begin{array}{l}123.3 \\
(95.5-159.0)\end{array}$ & $\begin{array}{l}157.1 \\
(120.4-223.6)\end{array}$ & .006 \\
\hline AVVR & & & .003 \\
\hline None/mild & $329(78)$ & $10(48)$ & \\
\hline Moderate/severe & $94(22)$ & $11(52)$ & \\
\hline $\begin{array}{l}\text { Death during stage II } \\
\text { hospitalization } \\
\text { among subjects } \\
\text { surviving to stage II }\end{array}$ & & & \\
\hline No & $367(98)$ & $14(64)$ & $<.001$ \\
\hline Yes & $9(2)$ & $8(36)$ & \\
\hline
\end{tabular}

With the exception of shunt type, only differences in characteristics between discharged and nondischarged subjects with $P<.05$ are presented. Fisher exact test was used to compare subject groups for variables that are dichotomous or categoric. The Wilcoxon rank-sum test was used to compare subject groups for continuous variables that are skewed. Student 2-sample $t$ test was used for continuous variables that are not skewed. RVPAS, Right ventricle-to-pulmonary artery shunt; $M B T S$, modified Blalock-Taussig shunt; $I Q R$, interquartile range; $E C M O$, extracorporeal membrane oxygenation; $C P B$, cardiopulmonary bypass; $C P R$, cardiopulmonary resuscitation; $P A$, pulmonary artery; $S A E$, serious adverse event; $G$, gastrostomy; $G J$, gastricjejunal; $N G$, nasogastric; $N J$, nasojejunal; $A V V R$, atrioventricular valve regurgitation. 